\title{
Chemical Profile, Agaritine and Selenium Content of Agaricus bisporus
}

\author{
Eman Mostafa Mohamed* \\ Botany Departmen; Faculty of Science; Assiut University; Assiut - Egypt
}

\begin{abstract}
Chemical profile of the Agaricus bisporus samples were analyzed using GC/MS method in ethanolic extracts. A total of 174 metabolic products were detected, which included 13 significant metabolites between 1.2 to $83 \%$ (w/w); other 13 metabolites at $1 \%(w / w)$ and 148 metabolites less than $1 \%$ classified into 12 categories. These metabolites had many medicinal activities, which included anti-cancer, anti-cardiovascular diseases, anti-hypercholesterol, anti-microbial, hepatoprotective, human health supporting and immune enhancer. HPLC analysis of water extracts of the A. bisporus samples showed that the spores and gills in the fresh adult mushroom had higher percentage of agaritine mycotoxin than the other parts. These contents were decreased by different treatments especially by boiling, preservation and cooking. The selenium contents ( $p p b)$ was measured by Galvanometric analysis and highest content was recorded in fresh whole mushroom sample (0.97) followed by cooked preserved (0.4) and fried sample (0.11).
\end{abstract}

Key words: Agaricus bisporus, chemical profile, agaritine, selenium, anticancer, antihypercholesterol, aroma compounds, Galvanometric, GC/MS and HPLC

\section{INTRODUCTION}

Agaricus bisporus (Lange) Imbach is the most wild and cultivated edible mushroom and represents more than $40 \%$ of world production of mushrooms (Callac et al. 2000; Carluccio 2003). It is cultivated in over 70 countries and on every continent, except Antarctica. The global production in 1990s was more than $\$ 800$ million/year (Andersson and Gry 2004) and increased to $\$ 12,250$ in 2002 (UN 2010). A. bisporus has delicious taste, high nutritional value, high aroma or flavoring taste and is used as a food and in food industries (Mattila et al. 2010). It has high biological activity, low toxicity and is used in folk classical medicines, flavouring of food products, perfume, cosmetics and pharmaceutical industries, as defoaming agents and to improve the shelf life and safety of minimally processed fruits (Caglarırmak 2009; Dastager 2009; WFI, $2011_{\text {c\&d }}$ ). The wild A. bisporus were referred for cocustomer due to their flavor and texture (Sadiq et al., 2008). A. bisporus has many medicinal metabolites responsible for the therapeutic activity for which the treatment and prevention of many human diseases act as anti-cancer agents such as polysaccharides, fatty acids and ergosterol, N,N,Ntris"hydrazine carbonyl" phosphoric triamide, selenium and vaccenic acid; anti-hyper cholesterol agents (fatty acids, glycoproteins, sterols and vaccenic acid); anti-microbial agents (agaritine and alcohols); anti-cardiovascular disease metabolites (fatty acids, sterols and pyran derivative); hepato protective agent (triterpenoids); human health supporting agent's (fatty acids,

*Author for correspondence: emanscience@gmail.com 
sterols and sugar alcohols); immune enhancer metabolites (fatty acids, glycoproteins, polysaccharides and sterols). These medicinal metabolites such as $\beta$-glucan and G-glucan; polysaccharide $\mathrm{K}$ or PSK "protein bound polysaccharide"; phenols; polyketides, triterpenoids and sterols (De Barros, 2008); PSK (UN 2010); triterpenoids, lectins glycoprotein's (WU et al. 2007; USCDC 2009; UN 2010); ergothioneine (Ey et al. 2007; Borchers et al. 2008); selenium (Shi et al. 2002; Gergely et al. 2005); pyran derivative (SCB, 2007-2010); essential fatty acids (Andersson and Gry 2004; Ji, et al. 2006) and eicosanoids (WFI 2011 $1_{\mathrm{e}}$ ).

Essential fatty acids in A. bisporus act against aromatase enzyme which used in estrogen production. Estrogen responsible for the development of breast cancer. The women who consumed more than $10 \mathrm{~g}$ of fresh A. bisporus daily, were $64 \%$ less likely to develop breast cancer, while those that combined a mushroom diet with regular green tea, reduced the risk of breast cancer by nearly $90 \%$ (Chen et al. 2006; Hong et al. 2008).

A. bisporus contains small amounts of the carcinogenic mycotoxin agaritine, which is a health hazard. It is water soluble, has antiviral and mutagenic activity on Salmonella typhimurium. It is metabolized into its highly reactive diazonium ion, which modifies DNA through a radical mechanism. Its $\mathrm{LD}_{50}$ toxicity is between $1-10$ $\mathrm{mg} / \mathrm{kg}$. Agaritine are synthesized in mycelium and translocated into the fruiting body. The highest amounts were found in the fresh cap and the gills of the fruiting body, especially in the spores. It is synthesized from P-hydroxybenzoic acid absorbed from the lignin in the substrates, hydrazine formed by the oxidative coupling of two amines via a phenolic radical mechanism through shikimate pathway from glutamic acid. It oxidizes rapidly upon storage, however, totally degrades after $48 \mathrm{~h}$ in aqueous solution with exposure to air. The degradation of agaritine is affected by many factors, including the amount, heat treatment, preservation, time of storage and the decreases by cooking up to $90 \%$ or storage in water (Andersson and Gry 2004; Janak et al. 2006; Roupas, et al. 2010; WFI 2011 $1_{\mathrm{a}}$ ).

This investigation was designed to study the chemical profiles of the A. bisporus and factors affecting its quality, (nutritional, medicinal, flavoring value). These factors included its consumption as fresh, preserved or cooked boiled, fried or heat treated. Also, the study was designed to detect and identify the most significant metabolites such as anti-cancer, antihypercholesterol, other human health supporting agents, and aroma compounds. The harmful effects of agaritine mycotoxin and how to avoid such effects are discussed. Selenium as antioxidant agent was also studied.

\section{MATERIALS AND METHODS}

The agaritine and ethanol of analytical grade were obtained from Sigma-Aldrich-Company. ICollection of A. bisporus samples- Different fresh samples of $A$. bisporus were collected from the market (a maximum of 1 - 2 days old) in Assiut Governorate, Egypt. These samples were originated from the spores obtained from the Agricultural Egyptian Ministry. This strain was deposited in Assiut University Mycological Center Culture Collection with AUMC No. 8060.

II-Treatment and preparation of A. bisporus for chemical analysis-

a) Fresh samples of the whole mushroom, caps, gills and stalks were divided into $25 \mathrm{~g}$ for each of the following treatment-

*Cooking either by frying for $5 \mathrm{~min}$. in vegetable oil or boiling for $10 \mathrm{~min}$. using the whole mushroom samples.

*Mushroom samples from whole, caps, gills and stalks were used without cooking.

b) Preserved samples (in water, $\mathrm{NaCl}$ and citric acid) of the whole A. bisporus were also collected from the markets and divided $25 \mathrm{~g}$ each into uncooked (from two different brands) and cooked for $15 \mathrm{~min}$ an oven at $120^{\circ} \mathrm{C}$ (only one brand).

III-Extraction of the samples- From each sample, $25 \mathrm{~g}$ were homogenized for $10 \mathrm{~min}$. in a high-speed blender at $16.000 \mathrm{rpm}$ with $500 \mathrm{ml}$ ethanol and $25 \mathrm{~g}$ with water. The extraction procedure was repeated three times. The ethanolic extracts were combined, washed, filtered, and concentrated to near dryness.

$I V-G C / M S$ Analysis- The metabolites in the ethanolic extracts of all the samples were detected using GC/MS analysis: 250g fresh whole mushroom were also used for the GC/MS analysis (Mattila et al. 2010).

$V$-Agaritine content were determined in water extract by HPLC- As disscued by Nagadka et al., (2006). 
VI-Galvanometric methods for determination of selenium was determined following Shi et al., (2002) and Gergely et al. (2005).

\section{RESULTS AND DISCUSSION}

Table 1 and Figures 1and 2 shows the chemical analysis of fresh, cooked and preserved ethanolic and water extracts of A. bisporus using different detection methods. There were 18 metabolites in the ethanol extract in addition to agaritine in the water extract; selenium was detected by the Galvanometric methods. Numerous studies showed that these metabolites have medicinal activity (Wang et al. 2007; WU et al. 2007; USCDC 2009; UN 2010), which include anticancer agents such as fatty acids poly saccharides, and ergosterol (Takaku et al. 2001; Ren et al. 2008; Koyyalamudi et al. 2009); N,N,N-tris (hydrazinecarbonyl) phosphoric triamide, selenium and vaccenic acid (Shi et al. 2002; Sosnovsky and Rao 2004; Gergely et al. 2005; De Barros 2008; Mattila et al. 2010); antihypercholesterol agents such as fatty acids, glycoproteins, sterols and vaccenic acid (Ey et al. 2007; Borchers et al. 2008; De Barros 2008); antimicrobial agents such as agaritine and alcohols (Janak, et al. 2006; Nagadka, et al. 2006; Roupas, et al. 2010); anti-cardiovascular disease agents such as fatty acids, sterols and pyran derivative (SCB, 2007-2010); human health supporting agent's such as fatty acids, sterols and sugar alcohols (Andersson and Gry 2004; Ji, et al. 2006); immune enhancer agents such as fatty acids, glycoproteins, polysaccharides and sterols (UN, 2010); hepato-protective agent such as triterpenoids (De Barros 2008) and food flavoring or aroma metabolites such as alcohols, aldehydes, amides, amines, carboxylic acid, esters, ketones, terponoids, thiols and mercapto (Mattila, et al. 2010). Linoleic acid was recorded at $12.2 \%$ in the whole fresh sample; $1.5 \%$ in the stalks; $0.8 \%$ in the gills but was completely absent in the samples treated by heat and preserved. By GC/MS analysis of A. bisporus, Chen et al. (2006) recorded 0.21 linoleic, 0.28 linolenic and $0.39 \mathrm{mmol} / \mathrm{L}$ of oleic acid, which were active against the breast cancer cells but myristic $(3.7 \%)$, palmitic $(3.8 \%)$ and stearic acid $(2.0 \%)$ had little activity. Amakura et al. $\left(2006_{\mathrm{a \& b}}\right)$ found that the linoleic acid was present in the water methanol extracts of mushroom by HPLC and spectroscopic analysis. Glycerol represented 5.8, 1.0, 0.5 and $0.3 \%$ in gills, caps, cooked preserved and fried, respectively. Caglarırmak (2009) has also reported the presence of glycerol in A. bisporus extract.

Three metabolites were detected only in the cooked preserved sample and included cyclobutyl alcohol at $64.7 \%$; 2,3-Dihydro-3,5-dihydroxy-6methyl-4H-pyrane-4-one at $10.3 \%$ and 2chloropropane at $0.7 \%$. Acetic, propionic, butyric and isobutyric acids stimulated the germination of A. bisporus spores. There are reports that these spores also contain phospholipids which includes $11.7 \%$ cardiolipin, $13.8 \%$ phosphatidie, $12.3 \%$ phosphatidyl ethanolamine, 39\% phosphatidylserine, $10.5 \%$ phosphatidyl inositol and $12.6 \%$ others metabolites (Osullivan and Losel 1971).

In the present study the N,N,N-tris(hydrazine carbonyl) phosphoric triamide was found in the gills $(5.9 \%)$ and in the fried sample $(0.5 \%)$. Sosnovsky and Rao (2004) studied that the structure and anti-cancer activity relationship among the various aliphatic and aromatic hydrazones which contained $\mathrm{N}, \mathrm{N}, \mathrm{N}^{\prime}, \mathrm{N}^{\prime}$-bis(1,2ethanediyl) phosphoric diamide moiety. All the 19 compounds were active aganist murine lymphocytic leukemia.

Four compounds were detected only in the fresh whole sample and included penadecylamine $(0.3 \%)$; 1-homoadamantane carboxylic acid $(0.2 \%)$; 4-butyl aniline $(0.04 \%)$ and ergosterol $(5.7 \%)$. The highest percentage of alantoic acid was present in the cooked preserved sample $(9.3 \%)$ followed by the boiled $(1 \%)$, gills $(0.8 \%)$ and fried $(0.6 \%)$. The lowest amount of the acid was present in uncooked preserved samples $(0.3 \%$ and $0.1 \%) .1,2,3,4,5,8,9,10,11,12,12,16$-dodecadibenzoid, di-[1,2,7,8] tetrathiacyclo dodecin was detected in all the tested samples except the samples of stalks, where it was $6.0 \%$ in the cooked preserved and $0.3 \%$ in II uncooked preserved samples. 3-chloro-N-methylpropyl amine was detected only in the preserved samples which was $5.9 \%$ in the cooked preserved and $1.9 \%$ in the fresh sample. Glycinamide was detected in the all tested samples, except in the cooked and I uncooked preserved sample and fluctuated between 3.5 - $69.1 \%$. The high levels were recorded in the different parts of mushroom which were $69.1 \%$ in the gills, $43.3 \%$ in the stalk, $39.5 \%$ in the fried, $24.6 \%$ in the boiled, $14.2 \%$ in the caps, $5.6 \%$ in the whole fresh and $3.5 \%$ in the 
preserved samples. 2R,3S-9-[1,3,4-trihydroxy2tutoxymethyl] guanine was recorded in the fresh whole sample (1.4\%) and fried samples (1.6\%).

L-glutamic acid was recorded in the all tested samples except the cooked preserved sample and the highest percentage was in the caps sample $(53.4 \%)$ followed by the gills $(41.9 \%)$ and stalks $(12.5 \%)$. But the levels of L- glutamic acid were decreased in the treated A. bisporus samples (boiled $5 \%$ ), uncooked preserved samples $(3.0 \%$, $1.9 \%)$, fresh whole $(1.5 \%)$ and fried $(0.7 \%)$. De Barros (2008) studied that the ethanolic extract of the fruiting bodies of $A$. bisporus and found that alanine, glutamic, proline and arginine were the predominant free amino acids. Also, ornithine, $\mathrm{N}$ ( $\gamma$-L-glutamyl)-4hydroxyaniline and $\gamma$-amino butyric were the most free amino acids. Pidolic acid had high percentage in the cooked preserved (19.9\%) followed by the boiled (2.6\%), fried $(2.1 \%)$, uncooked preserved (1.9 and $1.5 \%)$ and whole fresh $(0.7 \%)$.

D-mannitol was recorded in high amount in all the tested samples, representing $95.8 \%$ in the uncooked preserved I and $90.6 \%$ in II, boiled $73.7 \%$, fried $68.9 \%$, whole fresh $63.7 \%$, cooked preserved $42.7 \%$ and stalk $16.6 \%$. These results were similar with the results reported by De Barros (2008).

SH-indenol [1,2-b] pyridine-5-one (3.8\%) and 1methyl-2-phenoxyethylamine $(0.9 \%)$ were recorded only in the caps sample.

Palmitic acid was recorded in $5.9 \%$ in the whole fresh, $0.3 \%$ in the gills and $0.29 \%$ in the stalk samples but it was completely absent in other tested samples. De Barros (2008) found that A. bisporus had high levels of polyunsaturated fatty acids such as palmitic, stearic and linoleic acid in most edible wild species. Linoleic acid is the precursor of 1-octen-3-ol. which is the principal aromatic compound and contributes to flavor. Carbonates from the alcohols, dialkylazodi carboxylate and tris (dimethylamino) phosphine ranged from 22-88\% (Grynkiewicz et al. 1975).

Table 1 and Figure I showed the agaritine percentage in A. bisporus tested samples. They were $0.26,0.22,0.20$ and $0.19 \%$ in the whole fresh sample, gills, caps and stalk, respectively. These results were in agreement with other studies on the agaritine content in different parts of A. bisporus.
Schulzová et al., (2002) tested 28 samples of fresh A. bisporus with a cup diameter of 4-6 $\mathrm{cm}$ and found that the agaritine content fluctuated between $165-457 \mathrm{mg} / \mathrm{kg}$ fresh weight. Andersson and Gry (2004) studied the presence of agaritine in various parts of the fruit body of the of the whole mushroom and found that the original agaritine levels in the fresh A. bisporus fluctuated between $228.2-720 \mathrm{mg} / \mathrm{kg}$ fresh weight, $(12,16$, and $56 \%$ in the cap with its skin, skin of the cap and stalk and gills, respectively) $330-1730 \mathrm{mg} / \mathrm{kg}$ fresh weight in 14 lots from 10 different growers. Janak et al., (2006) recoded that the gills with the spores of A. bisporus had large percentage of agaritine fluctuating between $0.003-0.304 \%$ more than other parts.

Agaritine content were decreased by the heat treatments and preservation $(0.26 \%$ in the whole fresh decreased by boiling to $0.2 \%$; cooking and preservation to $0.12 \%$ and by frying to $0.1 \%$ ). These results were similar with the results recorded by many other authors. Hashida et al., (1990) found that boiling at $100^{\circ} \mathrm{C}$ significantly decreased the level of agaritine about 57 and $75 \%$ after 5 and $10 \mathrm{~min}$, respectively but the percentage were reduced 55, 60, 75 and 90\% after 5, 10, 60 and $120 \mathrm{~min}$, respectively. Schulzová et al., (2002) found that the dry baking during pizza making, reduced the agaritine content by about $25-50 \%$; frying at $100^{\circ} \mathrm{C}$ for $5 \mathrm{~min}$ reduced 34 and $69 \%$ in the vegetable oils and butter, respectively but frying at $150{ }^{\circ} \mathrm{C}$ for $10 \mathrm{~min}$. reduced the content by $57 \%$. Only 2.8 and $0.6 \%$ of the original content could be recovered in the butter and oil, respectively (Hajšlová, et al. 2002).

Agaritine percentage were decreased by preservation and fluctuated between $0.44-0.97 \%$ (Table 1 and Fig. 1). These results were in agreement with Andersson and Gry, (2004) who recorded that the agaritine percentage were decreased by $68 \%$ by preservation for five days. The storage at $4{ }^{\circ} \mathrm{C}$ resulted the agaritine content of two batches as 440 and $720 \mathrm{mg} / \mathrm{kg}$, respectively. After one week, one of the batches had lost $2 \%$ of its content, but another batch lost $47 \%$ and after two weeks were 36 and $76 \%$, respectively (Ross et al., 1982). Storage at $5^{\circ} \mathrm{C}$ reduced the content to 25,40 and $50 \%$ after 6,10 and 14 days, respectively (Schulzová et al. 2002). 


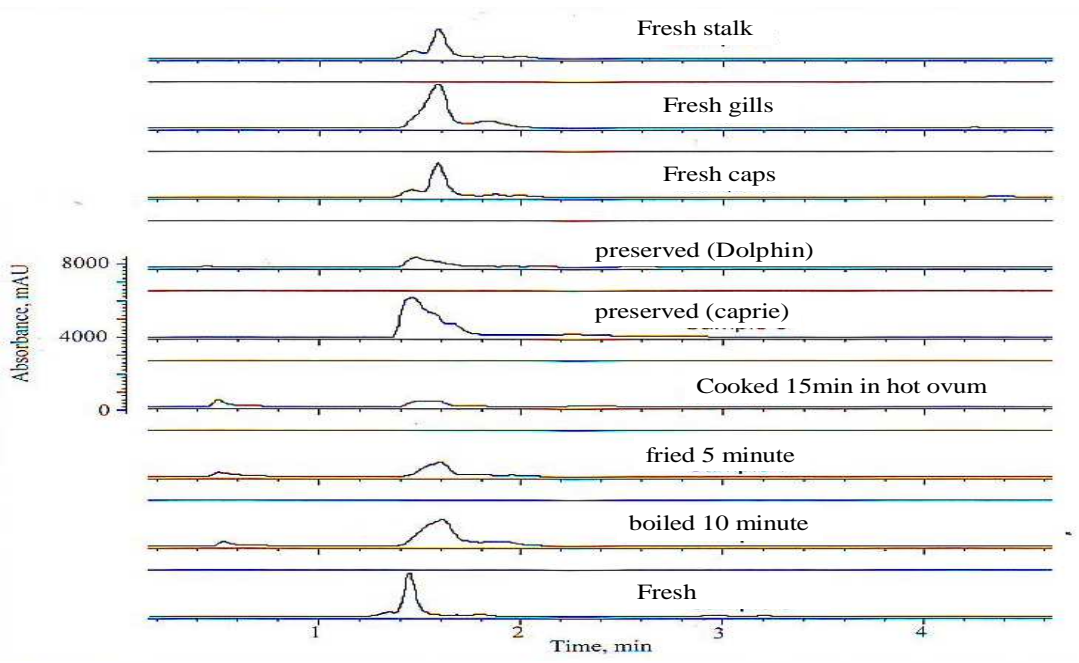

Figure 1- Agaritine mycotoxin (\% w/w) detected by HPLC analysis in water extracts of $A$. bisporus samples.

Table 1- Detectable metabolites in the tested mushroom samples $(\% \mathrm{w} / \mathrm{w})$ in ethanolic extracts, agaritine $(\% \mathrm{w} / \mathrm{w})$ in water extract and selenium (ppb).

\begin{tabular}{|c|c|c|c|c|c|c|c|c|c|c|}
\hline & \multirow{4}{*}{ a- Metabolites detected (as \% w/w) } & \multicolumn{9}{|c|}{ Mushroom samples treated } \\
\hline & & \multicolumn{4}{|c|}{ Fresh parts } & \multirow{2}{*}{\multicolumn{2}{|c|}{ Cooked }} & \multicolumn{3}{|c|}{ Preserved } \\
\hline & & \multirow{2}{*}{ Whole } & \multirow{2}{*}{ Caps } & \multirow{2}{*}{ Gills } & \multirow{2}{*}{ Stalks } & & & \multicolumn{2}{|c|}{ Uncooked } & \multirow{2}{*}{ Cooked } \\
\hline & & & & & & Fried & Boiled & I & II & \\
\hline 1 & D-Mannitol & 63.7 & & & 16.6 & 68.9 & 73.7 & 95.8 & 90.6 & 42.7 \\
\hline 2 & Glcinamide & 5.6 & 39.5 & 43.3 & 69.1 & 24.6 & 14.2 & & 3.5 & \\
\hline 3 & L-Glutamic acid & 1.5 & 53.4 & 41.9 & 12.5 & 0.7 & 5.0 & 1.9 & 3.0 & \\
\hline 4 & Pidolic acid & 0.7 & & & & 2.1 & 2.6 & 1.9 & 1.5 & 19.9 \\
\hline 5 & Linoleic acid & 12.2 & & 0.8 & 1.5 & & & & & \\
\hline 6 & 2,3-Dihydro-3,5-2OH-6-CH3-4H-pyrane-4-one & & & & & & & & & 10.3 \\
\hline 7 & Alantoic acid & & & 0.8 & & 0.6 & 1.0 & 0.1 & 0.3 & 9.3 \\
\hline 8 & $\begin{array}{l}\text { 1,2,3,4,5,8,9,10,11,12,12,16-dodecadibenzoid, } \\
{[\mathrm{d}, \mathrm{i}][1,2,7,8] \text { - tetra thiacyclododecin }}\end{array}$ & 0.9 & 1.5 & 1.1 & & 0.8 & 3.6 & 0.3 & 1.1 & 6.0 \\
\hline 9 & $\mathrm{~N}, \mathrm{~N}, \mathrm{~N}$-tris(hydrazinocarbonyl) phosphoric triamide & & & 5.9 & & 0.5 & & & & \\
\hline 10 & Palmitic acid & 5.9 & & 0.3 & 0.3 & & & & & \\
\hline 11 & Glycerol & & 1.0 & 5.8 & & 0.3 & & & & 0.5 \\
\hline 12 & Ergosterol & 5.7 & & & & & & & & \\
\hline 13 & Cyclobutyl alcohol & & & & & & & & & 4.7 \\
\hline 14 & 2-Chloropropane & & & & & & & & & 0.7 \\
\hline 15 & 3-Chloro-N-methylpropylamine & 1.9 & & & & & & & & 5.9 \\
\hline 16 & 2R,3S-9-[1,3,4-trihydroxy-2-tutoxymethyl] guanine & 1.4 & & & & 1.6 & & & & \\
\hline 17 & 5H-Indenol[1,2-b]pyridine -5-one & & 3.8 & & & & & & & \\
\hline 18 & 1-Methyl-2-phenoxyethylamine & & 1 & & & & & & & \\
\hline b- $A$ & garitine $(\% \mathrm{w} / \mathrm{w})$ & 0.26 & 0.20 & 0.22 & 0.20 & 0.10 & 0.20 & 0.1 & 0.04 & 0.12 \\
\hline $\mathrm{c}-\mathrm{S}$ & lenium (ppb) & 0.97 & 0.08 & 0.1 & 0.10 & 0.10 & 0.03 & $<0.01$ & $<0.01$ & 0.40 \\
\hline
\end{tabular}


Table 2- The chemical profile of the whole fresh A. bisporus samples.

\begin{tabular}{|c|c|c|c|c|}
\hline No. & Detectable metabolites & $\% \mathrm{w} / \mathrm{w}$ & No & Detectable metabolites \\
\hline 1 & Ergosterol & 83.0 & 47 & 1-Butanamine,2-methyl-n-(2-methlbutylidene)- \\
\hline 2 & D-Mannitol & 63.0 & 48 & 13-Octadecenal, Octadecane,1-(ethenyloxy)- \\
\hline 3 & Glcinamide & 39.4 & 49 & Cyclododecane \\
\hline 4 & L-Glutamic acid & 27.3 & 50 & 7-Pentadecyne \\
\hline 5 & 2-mono-linolein, & 10.0 & 51 & $\begin{array}{l}\text { 3-(1,3-Di-OHisopropyl)-1,5,8,11,14,17- } \\
\text { hexaoxacyclononadecane }\end{array}$ \\
\hline 6 & $\mathrm{~N}, \mathrm{~N}, \mathrm{~N}$-tris(hydrazine ocarbonyl) phosphoric triamide & 6.0 & 52 & $\begin{array}{l}\text { 3-[N-[3-Diethylaminopropyl]-1-cyclopentenylamino] } \\
\text { propionitrile }\end{array}$ \\
\hline 7 & Linoleic acid & 4.2 & & 4] Amides \\
\hline 8 & 5H-Indenol[1,2-b]pyridine -5-one & 4.0 & 53 & (Z)-13-Docosenamide, \\
\hline 9 & Glycerol & 3.4 & 54 & 2-Myristynoyl-glycinamide \\
\hline 10 & Palmitic acid & 2.2 & 55 & 9-Octadecenamide \\
\hline 11 & 3-Chloro-N-methylpropyl amine & 2.0 & 56 & N,N-bis(2-hydroxyethyl)-dodecanamide, \\
\hline 12 & 2-mono-palmitin & 2.0 & 57 & $\mathrm{~N}$-(2-hydroxyethyl)-decananamide, \\
\hline 13 & $\begin{array}{l}\text { 1,2,3,4,5,8,9,10,11,12,12,16-dodecadi benzoid, } \\
\text { di }[1,2,7,8] \text {-tetrathiacyclo dodecin }\end{array}$ & 1.2 & $\begin{array}{l}58 \\
59\end{array}$ & $\begin{array}{l}\text { N,N-di(isopropyl)-O-ethyl phosphonodiamide, } \\
\text { N-allyl-hexanamide, }\end{array}$ \\
\hline 14 & Alantoic acid & 1.0 & & 5] Amines \\
\hline 15 & 1-Methyl-2-phenoxyethylamine & 1.0 & 60 & Acetyl-leucine \\
\hline 16 & 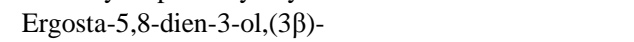 & 1.0 & 61 & Agaritine \\
\hline 17 & 7,22-Ergostadienol & 1.0 & 62 & 4-Butyaniline \\
\hline 18 & $\gamma$-Ergostenol & 1.0 & 63 & D-alloisoleucine \\
\hline 19 & N-hexadecanoic acid & 1.0 & 64 & 2-chloro-N,N-dimethyl-ethanamine, $\mathrm{D}_{1}$-norleucine \\
\hline 20 & 9,12-Octadecadecanoic acid, ethyl ester & 1.0 & 65 & $\begin{array}{l}\text { 4-Dehydroxy-N-(4,5-methylenedioxy-2-nitro benzyli } \\
\text { dene)tyramine }\end{array}$ \\
\hline 21 & Carbonic acid,2-dimethylaminoethylpropyl ester & 1.0 & 66 & 2,5-Diisopropylpiperazine \\
\hline 22 & 2R,3S-9-[1,3,4-trihydroxy-2-tutoxymethyl] guanine & 1.0 & 67 & D-norleucine \\
\hline 23 & 16,28 -Secosol anidan-3-ol, $(3 \beta, 5 a)-$ & 1.0 & 68 & $\begin{array}{l}\text { 4-Fluorobenzyl(3-(4-luorobenzylsulfanyl) -[1,2,4] triazol-4- } \\
\text { yl]amine }\end{array}$ \\
\hline 24 & Pidolic acid & 1.0 & 69 & Indolizine \\
\hline 25 & Propan-1-one,3-nitro-1-phenyl- & 1.0 & 70 & Isoleucine \\
\hline 26 & 1,5-Anhydro-d-mannitol & 1.0 & 71 & 2R,3S-9-[1,3,4-trihydroxy-2-tutoxymethyl]guanine \\
\hline \multicolumn{3}{|c|}{$\begin{array}{l}\text { The following metabolites were detected at less than } 1 \% \\
\text { 1] Alcohols }\end{array}$} & 72 & 2-Hydrazino-8-hydroxy-4-phenylquinoline \\
\hline 27 & 1,5-Anhydroglucitol & & 73 & 5H-indeno[1,2-b]pyridine \\
\hline 28 & 1,5-Anhydro-d-mannitol & & 74 & N-ethyl-2-carbomethoxyazetidine \\
\hline 29 & Benzyl alcohol & & 75 & 1-Methyl-2-phenoxyethylamine \\
\hline 30 & Cholesterol & & 76 & Penadecylamine \\
\hline 31 & (3. $\beta, 22 \mathrm{E})$-ergosta-5,8,22-trien-3-ol & & 77 & Piperine \\
\hline 32 & 8(14),22-Ergostadienol & & \multicolumn{2}{|r|}{ 6] Carboxylic acids } \\
\hline 33 & (3.ß.)-ergosta-5,24(28)-dien-3-ol & & 78 & 1,2-Benzenedicarboxylic acid, \\
\hline 34 & 4,4-dimethyl-(3. $\beta, 5 x)$-cholesta-7,14-dien-3-ol, & & 79 & Benzoic acid \\
\hline 35 & Ergost-4,7,22-trien-3. $\square .-$ ol & & 80 & Carpic acid=Decanoic acid \\
\hline 36 & (3.ß.)-Ergosta-5,8-dien-3-ol, & & 81 & Cis-Vaccenic acid \\
\hline \multirow[t]{2}{*}{37} & (3. $\beta$-a.5 $\square) 16,28$-Secosolanidan-3-ol & & 82 & 2-Dodecene-1-yl(-)succinic anhydride \\
\hline & 2] Aldehyde & & 83 & Hexadecanoic acid=Palmatic acid \\
\hline 38 & 4-Hydroxy-2-methylbenzaldehyde & & 84 & Oleic acid \\
\hline 39 & 2-Heptadecenal & & 85 & 3-Methyl-decanoic acid, \\
\hline 40 & 9-Octadecenal, & & 86 & Pentadienoic acid \\
\hline 41 & 2-octyl-cyclopropaneoctanal, & & 87 & Tridecanoic acid \\
\hline \multicolumn{5}{|c|}{ Trans-13-Octadecenal, } \\
\hline & 3]Alicyclic compound & & 88 & 1-Benzazirene-1-carboxylic acid,2,2,5a-trimethyl1a \\
\hline 43 & (1-octylnonyl)-cyclohexane, & & 89 & [3-oxo-1-butenyl] perhydro-methyl ester \\
\hline 44 & Ethanol, 2-(octadecyloxy)- & & 90 & 1Bis(2-ethylbutyl) ester \\
\hline 45 & Oxime-,methoxy-phenyl- & & 91 & Bis(4-methylpentyl) ester \\
\hline 46 & 1-(diethylboryl)-cyclooctane, & & 92 & Butyl 9,12-octadecadienoate \\
\hline
\end{tabular}


Cont. Table 2

\begin{tabular}{|c|c|c|c|}
\hline No. & Detectable metabolites & No. & Detectable metabolites \\
\hline \multirow[t]{2}{*}{93} & \multirow{2}{*}{$\begin{array}{l}\text { Ethyl 2-(2-chloroacetamido)-3,3,3-trifluoro-2-(4- } \\
\text { frluoroanilino)propionate }\end{array}$} & 134 & 1H-tetrazol-5-yl-pyrazine \\
\hline & & 135 & Oxirane,tetradecyl- \\
\hline 94 & 2-Butyric acid, 2-methoxy-3-methyl-,methyl ester & 136 & 2-Pyridineacetic acide, hexahydro- \\
\hline 95 & Butyric acid, 3-methyl-,hexadecyl ester & 137 & $\begin{array}{l}\text { Methanone,(1,3-benzodioxol-5-yl)(4-methyl-6-phenyl-1,5,2- } \\
\text { dioxazinan-2-yl) }\end{array}$ \\
\hline 96 & Carbonic acid,2-dimethylaminoethyl propyl ester & 138 & 2(3H)-Furanone,3-(2-bromoethyl)dihydro- \\
\hline 97 & Ditridecyl ester & 139 & 1,2,5-Oxadiazol-3-amino-e,4-(3-methoxyphenoxy)- \\
\hline 98 & Ethyl 9-hexadecenoate & 140 & Benzaldehyde,4-methoxy-3-(8-quinolinyloxymethyl)- \\
\hline 99 & Ethyl cyclohexanepropionate & 141 & 1,4-Naphthalenedione,2-amino-3-chloro- \\
\hline 100 & Ethyl acetoxycyanoacetate & 142 & 1-Naphthalenemethanol, 1,4,4a,5,6,7,8,8a-8H-2,5,5,8a-tetramethyl- \\
\hline 101 & 9(11)-Dehydroergosteryl benzoate & 143 & $\begin{array}{l}\text { 2-Oxabicyclo[4.4.1]dec-9-en-8-one,1,3,7,7-tetramethyl-,(-)- } \\
\text { (1R,3S,6R)- }\end{array}$ \\
\hline 102 & $\begin{array}{l}\text { Fumaric acid,2-dimethylaminoethyl heptadecyl } \\
\text { ester }\end{array}$ & 144 & Bacchotricuneatin c \\
\hline 103 & Fumaric acid,pent-4-en-2-yl tridecyl ester & 145 & $\begin{array}{l}\text { 2-Oxabicyclo[4.4.0]dec-9-en-8-one,1,3,7,7-tetramethyl-,(-)- } \\
\text { (1R,3S,6R)- }\end{array}$ \\
\hline 104 & Hexadecanoic acid,bis (2-ethylhexyl) ester & & 9] Ketones \\
\hline 105 & Hexadecanoic acid,2-3-di-OH-propyl ester & 146 & $\begin{array}{l}\text { 3-Chlorooxanilic acid N-(3-ethoxy-4-hydroxybenzylidene) } \\
\text { hydrazide }\end{array}$ \\
\hline 106 & Hexadecanoic acid,2-OH-1-(OH-methyl) ethyl ester & 147 & 2,3-Dihydro-3,5-dihydroxy-6-methyl-4H-pyrane-4-one \\
\hline 107 & Methyl 19-methyl-eicosanoate & 148 & 2,3-Dihydro-3-methyl-4H-1,3-benzothiazine-2-thione-4-one \\
\hline 108 & Mono(2-ethylhexyl) ester & 149 & 5H-Indenol[1,2-b]pyridine-5-one \\
\hline 109 & 1-Naphthoic acids, 2,4,6-trichlorophenyl ester & 150 & Octabenzone \\
\hline 110 & Oleyl alcohol,heptafluorobutyrate & 151 & Oxacyclododecan-2-one \\
\hline 111 & Oxalic acid, monoamide,N-allyl-,tetradecyl ester & 152 & 1-(3-hydrohy-3-phenyl-1-triazenyl)-antra-9,10 quinone, \\
\hline 112 & Oxalic acid,pentadecyl propyl ester & 153 & 2-Methyl-cyclodododecanone \\
\hline 113 & $\begin{array}{l}{[1,2,4] \text { Triazolo[1,5-a]pyrimidine-6-carboxylic }} \\
\text { acid,4,7-dihydro-7-imino-,ethyl ester }\end{array}$ & 154 & $\begin{array}{l}\text { 5,24-Dimethyl-1,4,7,10,18,21-hexaoxa-15,24-diazacycloocta } \\
\text { cosane-11,1425,28-tetrone }\end{array}$ \\
\hline 114 & $\begin{array}{l}\mathrm{S}-[2-[\mathrm{N}, \mathrm{N}-\text { dimethylamino]N,N-dimethylcarbamoyl } \\
\text { thiocarbo hydroximate }\end{array}$ & & 10] Other metabolites \\
\hline \multirow[t]{2}{*}{115} & \multirow{2}{*}{$\begin{array}{l}\text { 1H-indole-2-carboxylic acid,6-(4-ethoxyphenyl)-3- } \\
\text { methyl-4-oxo-4,5,6,7-tetrahydro-isopropyl ester }\end{array}$} & 155 & 3-ChlorooxanilicacidN-(3-ethoxy-4-hydroxybenz ylidene)hydrazide \\
\hline & & 156 & 2,4-Dimethyl-benzo[h]quinoline, \\
\hline 116 & 2,4:3,5-Dimethylene-1-iditol diacetate & 157 & 2,4-Dimethyl-benzo[h], \\
\hline 117 & $\begin{array}{l}\text { 9,12-Octadecadecanoic acid (Z,Z)-,2-OH-1-(OH- } \\
\text { methyl)ethyl ester }\end{array}$ & $\begin{array}{l}158 \\
159\end{array}$ & $\begin{array}{l}\text { 2-amino-3-chloro-1,4-Naphthalenedione, } \\
\text { 1H-tetrazol-5-yl-pyrazine, }\end{array}$ \\
\hline 118 & 9,12-Octadecadecanoic acid, ethyl ester & & 11] Pyrans \\
\hline 119 & $\begin{array}{l}\text { Pentadienoic acid, 2-hydroxy-1-hydroxymethyl) } \\
\text { ethyl ester }\end{array}$ & 160 & B-D-glucopyranoside,methyl \\
\hline \multirow[t]{2}{*}{120} & Undecanoic acid,11-bromo-,undecyl ester & 161 & 2-H-pyran,2-(2-heptadecynyloxy)tetrahydro- \\
\hline & 8] Heterocyclic compounds & 162 & 2H-pyran-2-acetic acid, tetrahydro- \\
\hline 121 & Azetidine,2,2,3-tetramethyl- & & 12] Terpenes \\
\hline 122 & Azetidine,3-methyl-1-(1-methylethyl) & 163 & (3. $\beta$ )-lanost-8-en-3-ol,24-methylene, \\
\hline 123 & Carbazol & 164 & 2,4-difluoro-1-isocyanato-Benzene, \\
\hline 124 & 2,4-Dimethyl-benzo[h]quinoline, & 165 & 1-Docosene \\
\hline 125 & 1-Docosene & 166 & Ethyl-3-octene \\
\hline 126 & Eicosane & 167 & 3-Ethyl-3-octene \\
\hline $\begin{array}{l}127 \\
128\end{array}$ & $\begin{array}{l}\text { Eicosane,9-cyclohexyl- } \\
\text { Ethyl-3-octene 3-Ethyl-3-octene }\end{array}$ & $\begin{array}{l}168 \\
169\end{array}$ & $\begin{array}{l}\text { Methanamine,N-(1-methylbutylidene), } \\
\text { Glucitol,4,6-o-nonylidene- }\end{array}$ \\
\hline 129 & Geranyl nitrile & 170 & (3. $\beta$ )-lanost-8-en-2-ol,24-methylene-, \\
\hline 130 & 1,3,12-Nonadecatriene & 171 & 1-Nonadecene \\
\hline 131 & 3-methyl-1-(1-methylethyl)- azetidine, & 172 & Molybdenum,tricarbonyl $\left[(1,2,3,4,5,6-\beta)-\mathrm{H}_{3}\right.$ benzene $]-$ \\
\hline 132 & 1,4-Dioxin,2,3-dihydro- & 173 & 1,3,12-Nonadecatriene \\
\hline 133 & 1 H-indole,3-methyl- & 174 & Squalene \\
\hline
\end{tabular}



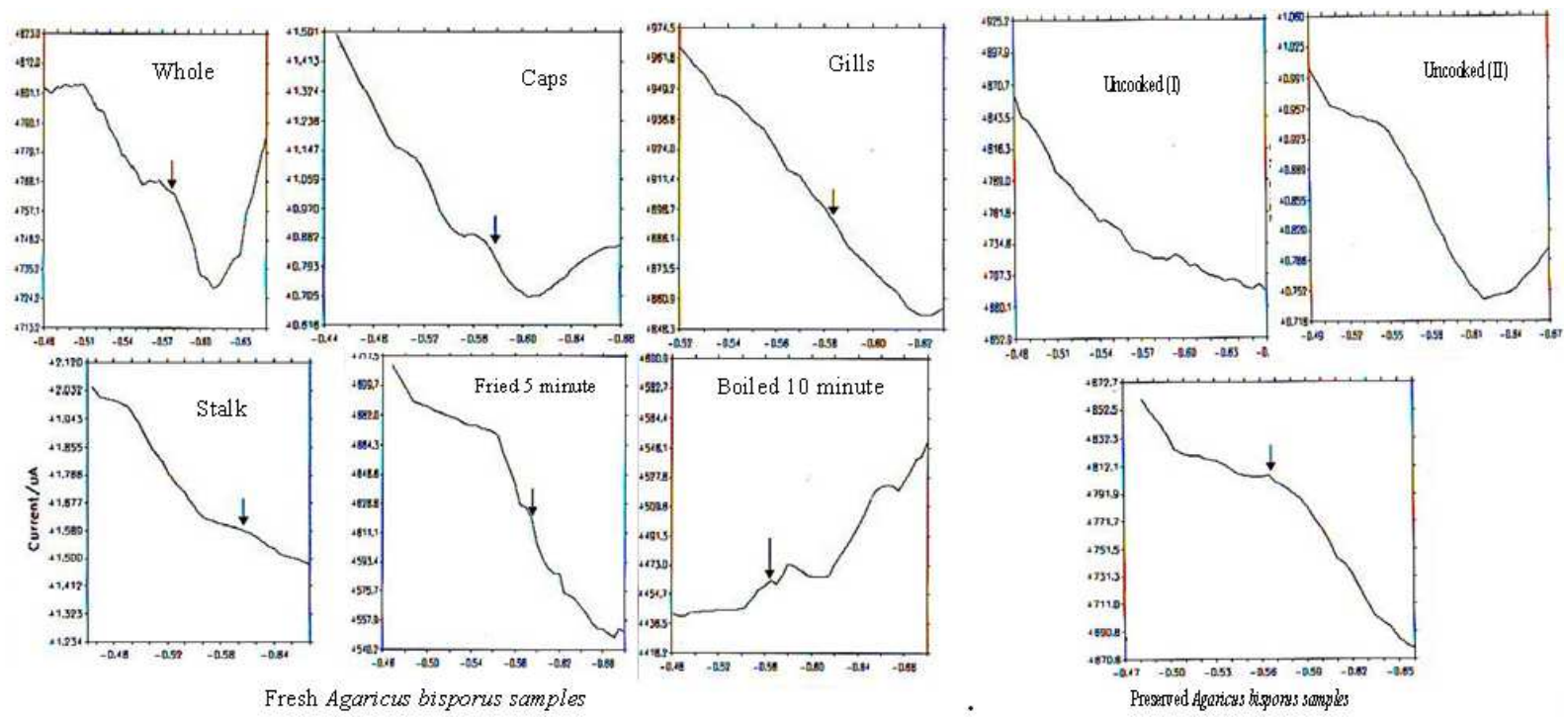

Figure 2 - Selenium (ppb) detected by Galvanometric method in A. bisporus samples.

The results indicated that the samples tested contained relatively low amounts of selenium. The high amount was recorded in the whole fresh samples $(0.97 \mathrm{pbb})$, followed by the fried $(0.11)$, stalks (0.1), caps (0.08), gills (0.05), cooked preserved (0.04) and boiled (0.03). On the other hand, the two uncooked preserved samples contained selenium $<0001 \mathrm{ppb}$. These results were similar to the results obtained by Shi et al. (2002) and Gergely et al. (2005), which showed 0.12-0.3 ppb selenium. The chemical profile of ethanolic extract of the fresh whole mushroom showed the presence of 174 metabolites out of which 13 had significant content from $1.2-83 \% ; 13$ as $1 \%$ and the remaining 148 metabolites were less than $1 \%$ $(\mathrm{w} / \mathrm{w})$. The significant significant metabolites were ergosterol (83\%), D-mannitol (63\%), glcinamide (39.4\%), L-glutamic acid (27.3\%), 2-monolinolein (10\%), N,N,N-tris(hydrazine ocarbonyl) phosphoric triamide $(6 \%)$, linoleic acid $(4.2 \%)$, 5H-Indenol[1,2-b]pyridine-5-one (4\%), glycerol (3.4\%), palmitic acid (2.2\%), 3-chloro-Nmethylpropyl amine (2\%), 2-mono-palmitin (2\%) and 1,2,3,4,5,8,9,10,11,12,12,16-dodecadibenzoid, di $[1,2,7,8]-$ tetrathiacyclo dodecin $(1.2 \%)$. Thirteen metabolites detected at $1 \%(\mathrm{w} / \mathrm{w})$ included alantoic acid; 1-methyl-2-phenoxyethyl amine;

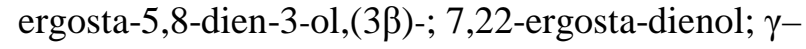
ergostenol; N-hexadecanoic acid; 9,12Octadecadecanoic acid ethylester; carbonic acid, 2-dimethylaminoethyl propylester; 2R,3S-9-[1,3,4- trihydroxy-2-tutoxy methyl]guanine; 6,28-secosolanidan-3-ol, $(3 \beta, 5 a)$-; pidolic acid; propan-1one,3-nitro-1-phenyl- and 1,5-Anhydro-dmannitol. Amakura et al. $\left(2006_{a}\right)$ reported that the oleic acid was the main unsaturated fatty acid in mushroom and there were saturated long-chain fatty acids such as linoleic, palmitic, and stearic, with eleostearic acid. Amakura et al., $\left(2006_{b}\right.$ ) reported that $A$. bisporus contained three novel conjugated long-chain fatty acids obtained from aqueous methanol extracts of mushroom together with nine known constituents of ostopanic acid as aroma compounds.

The remain 148 detected metabolites were classified into twelve categories according to the functional groups, which included alcohols 11, aldehydes 5, alicyclic 10, amides 7 , amines 18 , carboxylic acid 10, esters 33, heterocyclic 25, ketones 9, pyran 3, terponoids 12 and other metabolites 5. Tables showed that the five metabolites related to three sugar alcohol and its derivatives included glucitol, mannitol and sorbitol. Five amino acids glycine, leucine and their derivatives were detected. Forty seven metabolites were related to six fatty acids and their derivatives, which included butyric, carpic, linoleic, oleic, palmatic and pentadecyclic. Thirty two esters and sixteen metabolites related to four kinds of sterols (cholesterol, ergosterol, lanosterol and sitosterol) were detected. Eight metabolites contained thio group. These results were in 
agreement with the findings of other authors, Mattila et al., (2010) could identified aroma metabolites includes 13 alcohols, 16 aldehydes, 7 ketones and 20 heterocyclic their concentration was 8-611, 3-4850, 7-150 and 0.1-236 $\mu \mathrm{g} / 100 \mathrm{~g}$, respectively. Caglarırmak (2009) studied the $A$. bisporus in three flushes and at two different harvest times and found volatile components includes octadecanoic acid, hexadecanoic acid derivatives, and other important volatiles like dilimonene, n-nonane, benzen dicarboxylic acid, and cis-linoleic acid esters. De Barros (2008) studied A. bisporus and other 80 mushroom species and recorded that the detected metabolites act as a source of powerful new pharmaceutical metabolites includes polysaccarides ( $\beta$-glucan and G-glucans, PSK); phenolic metabolites (phydroxybenzoic acid, caffeic acid, p-coumaric acid, chlorogenic acid; rutin and epicorazins); polyketides, triterpenoids and sterols (butylated hydroxytoluene, butylated hydroxy anisole and Ftocoferol, caffeic acid); vitamines $\left(\mathrm{C}\right.$, thiamine- $\mathrm{B}_{1}$ and riboflavin $\left.-\mathrm{B}_{2}, \mathrm{D}_{2}\right)$. Since human civilization, fruiting bodies of mushrooms have been appreciated not only for texture and flavour but also for their chemical and nutritional properties. They are widely used as food flavouring ingredients in the soups. Their importance in the diet is not only for their nutritional and organoleptic values, but also for their pharmacological characteristics because they are rich in trace minerals, vitamins $\left(C\right.$, thiamine- $B_{1}$ and riboflavin $\left.-\mathrm{B}_{2}, \mathrm{D}_{2}\right)$ and have high water, protein, fibre, carbohydrate, etc [ $3-65 \%$ and nonstarch dietary fiber $3-32 \%$ of dry weight), low mono- and disaccharides, glycogen, insoluble fraction chitin, and have low fats (2-8\% of dry weight including, free fatty acids), sterols and their esters and phosphorus lipids]. These properties make them an excellent food for use in low caloric diets. Their protein contents is high (10 - 44\% of the dry weight) and they are also proven to be a good source of essential amino acids such as (leucine and valine as $25-40 \%$ of the total amino acids content, threonine, lysine, methionine and tryptophan) and non-essential amino acids (alanine, arginine, glycine, glutamic, aspartic, proline and serine). They act as a good source of $\mathrm{K}, \mathrm{Mg}, \mathrm{Ca}, \mathrm{Cu}, \mathrm{Fe}, \mathrm{Zn}$, and $\mathrm{P}$ and have low content of Na. Several other compounds have also been detected from A. bisporus as reported by numerous workers (Shi et al. 2002; Andersson and Gry 2004; Gergely et al. 2005; Ji, et al. 2006; Ey et al. 2007; WU 2007; Borchers et al. 2008; De Barros 2008; Sadiq et al. 2008; USCDC 2009; UN 2010).

\section{ACKNOWLEDEGMENTS}

Author thanks Prof A.H. Moubasher the critical revision of the manuscript. Prof M.S. Abady and all members of Analytical Chemistry Unit, Assiut University, Egypt are much acknowledged for help in the work.

\section{REFERENCES}

Amakura Y, Kondo K, Akiyama H, Ito H, Hatano T, Yoshida $\mathrm{T}$, et al. Characteristic long-chain fatty acid of Pleurocybella porrigens. Shokuhin Eiseigaku Zasshi. 2006 ; 47(4): 178-181.

Amakura Y, Kondo K, Akiyama H, Ito H, Hatano T, Yoshida $\mathrm{T}$, et al. Conjugated ketonic fatty acids from Pleurocybella porrigens. Chem Pharm Bull. 2006, 54(8): 1213-1215.

Andersson HC, Gry J. Phenylhydrazines in the cultivated mushroom Agaricus bisporus occurrence, biological properties, risk assessment and recommendations. Nordic Council of Ministers, Copenhagen. Tema Nord 558, Ekspressen Tryk \& Kopicenter. 2004; pp. 1-123.

Borchers AT, Krishnamurthy A, Keen CL, Meyers FJ, Gershwin ME. The immunobiology of mushrooms. Exp. Biol Med. 2008; 233(3): 259-276.

Caglarırmak N. Determination of nutrients and volatile constituents of Agaricus bisporus (brown) at different stages. J Sci Food Agric. 2009; 89: 634-638.

Callac P, Imbernon M, Guinberteau J, Pirobe L, Granit S, Olivier JM, Theochari I. Discovery of a wild Mediterranean population of Agaricus bisporus, and its usefulness for breeding work. Mushroom Sci. 2000; 15: 245-252.

Carluccio A. The complete mushroom book. Quadrille, 2003; pp 21-22.

Chen S, Oh S, Phung S, Hur G, Ye JJ, Kwok SL, et al., Antiaromatase activity of phytochemicals in white button mushrooms Agaricus bisporus. Cancer Res. 2006; 66 (24), 12026-12034.

Dastager SG. Aroma compounds. In: Nigam, PS, Pandey A. Biotechnology for Agro-Industrial Residues Utilization. Kerala India 2009; pp. 105-127.

De Barros LB. Chemical characterization and bioactive properties of portuguese wild edible mushrooms. [PhD Thesis]. De Farmacis: De SalamancaFac.University; 2008. 
Ey J, Schömig E, Taubert D. Dietary sources and antioxidant effects of ergothioneine. J Agric Food Chem. 2007; 55 (16): 6466-6474.

Gergely V, Kubachka kM, Fodor SM, Caruso JA. Selenium speciation in Agaricus bisporus and Lentinula edodes mushroom proteins using multidimensional chromatography coupled to inductively. Coupled plasma mass spectrometry. $J$ Chrom. 2005; A, 1-9.

Grynkiewicz G, Jurczak J, Zamojski A. The synthesis of mixed carbonates from alcohols, dialkylazodicarboxylate and tris(dimethylamino)phosphine. Tetrahedron. 1975; 31 (12): 1411-1414.

Hajšlová J, Hájková L, Schulzová V, Frandsen H, Gry J, Andersson HC. Stability of agaritine, a natural toxicant of Agaricus mushrooms. Food Addit Contam. 2002; 19: 1028-1033.

Hashida C, Hayashi K, Jie L, Haga S, Sakurai M, Shimizu H. Quantities of agaritine in mushrooms Agaricus bisporus and the carcinogenicity of mushroom methanol extracts on the mouse bladder epithelium. Nippon Koshu Eisei Zasshi. 1990; 37(6): 400-4005.

Hong SA, Kim K, Nam SJ, Kong G, Kim MK. A casecontrol study on the dietary intake of mushrooms and breast cancer risk among Korean women. J Intern Cancer. 2008; 122(4): 919-923.

Janak K, Stomer FC, Koller GE. The content of agaritine in spores from Agaricus bisporus. Food Chem. 2006; 99: 521-524.

Ji Y, Bi JN, Yan B, Zhu XD. Taxol producing fungi a new approach to industrial production of taxol in Chinese. Sheng Wu Gong Cheng Xue Bao. 2006; 22 (1): 1-6.

Koyyalamudi SR, Jeong SC, Song CH, Cho KY, Pang G. Vitamin $D_{2}$ formation and bioavailability from Agaricus bisporus button mushrooms treated with ultraviolet irradiation. J Agric Food Chem. 2009; 57 (8): 3351-3355.

Mattila P, Könkö K, Eurola M, Pihlava JM, Astola J, Vahteristo L, et al. Formation of flavor of dry champignons Agaricus bisporus L. J Appl Bioch Micro. 2010; 46 (1): 108-113.

Nagadka MH, Nagaoka H, Kondo K, Akiyama H, Maitani T. Measurement of a genotoxic hydrazine, agaritine, and its derivatives by HPLC with fluorescence derivatization in the Agaricus mushroom and its products. Chem. Pharm. Bull. 2006; 54 (6): 922-924.

Osullivan J, Losel DM. Spore lipids and germination in Agaricus bisporus. Arch Mikrobiol. 1971; 80: $277-$ 283.

Ren Z, Guo Z, Meydani SN, Wu D. White button mushroom enhances maturation of bone marrow derived dendrite cells and their antigen presenting function in mice. $J$ Nut. 2008; 138 (3): 544-550.
Ross AE, Nagel DL, Toth B. Occurrence, stability and decomposition of $\beta-\mathrm{N}[\gamma-\mathrm{L}(+)$-glutamyl $]-4$-hydroxy methyl phenylhydrazine agaritine from the mushroom Agaricus bisporus. Food Chem Toxicol. 1982; 20: 903-907.

Roupas P, Keogh J, Noakes M, Margetts C, Taylor P. Mushrooms and agaritine: A mini review. J Funct Foods. 2010; 2: 91-98.

Sadiq S, Bhatti NH, Hanif MA. Studies on chemical composition and nutritive evaluation of wild edible mushrooms. J Iran Chem Eng. 2008; 27 (3): 151-154.

SCB (Santa Cruz Biotechnology, Inc. Legal) 20072010.

Schulzová V, Hajšlová J, Peroutka R, Gry J, Andersson HC. Influence of storage and house hold processing on the agaritine content of the cultivated Agaricus mushroom. Food Addit Contam. 2002; 19: 853-862.

Shi YL, James AE, Benzie I.F, Buswell JA. Mushroom derived preparations in the prevention of $\mathrm{H}_{2} \mathrm{O}_{2}$ induced oxidative damage to cellular DNA. Terat. Carcinog. Mut. 2002; 22 (2): 103-111.

Sosnovsky G, Rao NU. Various aliphatic and aromatic hydrazones containing the N,N;N,N'-bis(1,2ethanediyl) phosphoric diamide moiety Research letter. WI 53201 USA new anticancer drugs. 2004.

Takaku T, Kimura Y, Okuda H. Isolation of an antitumor compound from Agaricus blazei Murill and its mechanism of action. $J$ nut. 2001; 131 (5): 14091413.

UN (United Nations) Training manual on mushroom cultivation technology. Economic and Social Commission for Asia and the pacific. China International Science and Technology Convention Centre $\mathrm{NO}_{12}$, Yumin Road, Chaoyang District, Beijing 100029, PR China, 2010.

USCDC (United State Centers for disease control) fruit and vegetable of the month, 2009.

Wang M, Etu J, Joshi S. Enhanced disruption of the blood brain barrier by intracarotid mannitol injection during transient cerebral hypoperfusion in rabbits. $J$ Neurosurg Anesthesiol. 2007; 19: 249-256.

WFI (Wikimedia Foundation, Inc.,): a) Agaritine; b) Agaricus bisporus; c) Glycerol; d) Aroma compound; e) Eicosanoids; f) Vaccenic acid. Available from: Wikipedia ${ }^{\circledR}$ is a registered trademark of the Wikimedia Foundation, Inc., a non-profit organization. 2012.

Wu D, Pae M, Ren Z, Guo Z, Smith D, Meydani SN. Dietary supplementation with white button mushroom enhances natural killer cell activity in C57BL/6 mice. J Nutr. 2007; 137(6): 1472-1477.

Received: April 18, 2011; Revised: November 04, 2011; Accepted: July 02, 2012. 